OPEN ACCESS

Edited by:

Michael Nadorff,

Mississippi State University,

United States

Reviewed by:

Christopher Drapeau,

Indiana University Bloomington,

United States

Melanie Walsh,

Mississippi State University,

United States

${ }^{*}$ Correspondence:

Yun-Xia Wang

cloudywang66@163.com

tThese authors have contributed equally to this work and share co-first

authorship

Specialty section: This article was submitted to Public Mental Health, a section of the journal

Frontiers in Psychiatry

Received: 17 November 2020 Accepted: 03 March 2021

Published: 06 April 2021

Citation:

Yu H-Z, Fu T, Zhou J-N, Ke P and Wang Y-X (2021) More

Depression-Related Public Concern

After the Suicide of a Pop Star in

China: Evidence From the Online Big

Data Platform.

Front. Psychiatry 12:629904

doi: 10.3389/fpsyt.2021.629904

\section{More Depression-Related Public Concern After the Suicide of a Pop Star in China: Evidence From the Online Big Data Platform}

\author{
Hong-Zhang $\mathrm{Yu}^{1+}$, Tian $\mathrm{Fu}^{2+}$, Jia-Nan Zhou ${ }^{1}$, Ping Ke ${ }^{3}$ and Yun-Xia Wang ${ }^{1 *}$ \\ ${ }^{1}$ Faculty of Psychology, Naval Medical University, Shanghai, China, ${ }^{2}$ Third Xiangya Hospital of Central South University, \\ Changsha, China, ${ }^{3}$ Air Force Hangzhou Special Service Recuperation Center Sanatorium Area 3, Hangzhou, China
}

Background: In China, we have seen dramatic increases in public concern over depression and mental health after the suicide of some famous persons. The objective of this study is to investigate the changes of search-engine query patterns to monitor this phenomenon based on the tragic suicide of a young Chinese pop star, Kimi Qiao.

Methods: The daily search volume for depression was retrieved from both the Baidu Index (BDI) and the Sina MicroBlog Index (SMI). Besides, the daily BDI for suicide, schizophrenia, obsessive-compulsive disorder, common cold, stomach cancer, and liver cancer were collected for comparison. According to the time of Qiao's suicide, all data were divided into two periods (i.e., Period One from 1 September 2015 to 31 August 2016 while Period Two ranged from 1 October 2016 to 30 September 2017). The paired $t$-test was used to compare the differences in search volumes between two periods. The Pearson correlation analysis was used to estimate correlations between the BDI and SMI for depression.

Results: The average BDI for depression, BDI for suicide, and SMI for depression in Period Two were significantly higher than in Period One $(p<0.05)$. There was a strong positive correlation between the BDI and SMI for depression $(r=0.97, p<0.001)$. And no significant difference in BDI for other diseases between the two periods was found.

Conclusions: The changes of search-engine query patterns indicated that the celebrity's suicide might be able to improve the netizens' concern about depression in China. The study suggests publishing more practical knowledge and advice on depression through the Internet and social media, to improve the public's mental health literacy and help people to cope with their depressive symptoms appropriately.

\footnotetext{
Keywords: depression, public concern, mental health literacy, health information, internet
} 


\section{INTRODUCTION}

Qiao, a young Chinese pop star with a sunny and positive image, was found dead at home on 16 September 2016 in Shanghai, China. Almost at the same time, rumors of his death from "extreme sexual experiences" went viral on the Internet, nearly paralyzing the Sina MicroBlog (i.e., the most popular microblog in China). Later, the agent of Qiao released that Qiao was suffering from depression prior to his suicide (1). People frantically discussed depression on social media and searched for online information about depression. Moreover, we found a phenomenon from Chinese media data that the public seems to be very interested in issues involving celebrity depression. In some sense, the Chinese general public does begin to pay more attention to depression. To confirm this, we carried out this study.

According to the Depression and Other Common Mental Disorders Global Health Estimates by the World Health Organization, China has the highest number of people with depression in the world (2). More than 300 million people, or over four percent of the global population, were living with depression in 2015 (2). The core symptoms of depression are depressed mood, a loss of energy, anhedonia, irritability, difficulties in concentrating, feelings of worthlessness, and abnormalities in appetite and sleep (3). Depression is associated with reduced quality of life, decreased physical and social function, increased risk of suicide, and elevated personal and social-economic burden $(4,5)$. Therefore, it is of great importance to diagnose and treat depression early. Both psychological treatments and pharmacotherapy has been demonstrated to have satisfactory effects on treating depressive disorders $(6,7)$. However, not all people with depression seek professional treatments, especially those living in developing and undeveloped countries $(8,9)$. Barriers to treatment for depression include high treatment expenditure, cultural values, social stigma, and lack of knowledge about available treatments (10). All these lead to a significant number of individuals struggling with depression having not been discovered nor treated (11).

Likewise, the treatment of depression is not very optimistic in China. A recent report by Guo et al. (12) claims that tens of millions of depressive patients in China have posed a huge challenge to the Chinese mental health service system with limited public resources. Miller and Zhen find that only $10 \%$ of those experiencing depressive symptoms would seek professional medical services, while $90 \%$ choose to talk with their families and friends or do nothing (13). They also reveal that more than $70 \%$ of people do not know there is an institution for psychotherapy, and only half the people have little understanding of depression regardless of age, gender, and education. In fact, most depressive patients first go to the non-psychiatric section of general hospitals for help rather than to psychiatric hospitals in China (14-16). In addition, studies show that Chinese depressive patients are reluctant to talk about their mental symptoms to physicians

Abbreviations: BDI, Baidu Index; SMI, Sina MicroBlog Index. because of traditional values and stigma, and the first things they often mention are the somatic symptoms (pain, gastrointestinal issues, weakness, and insomnia) (17-19). Fung et al. (20) also report that many Chinese people with mental illness do not seek help out of stigma and other unexplained reasons. Thus, it is urgent to promote the public's mental health literacy through proper channels (e.g., the Internet).

Nowadays, China has the broadest range of Internet users in the world. According to the 40th China Statistical Report on Internet Development, there were a total of 751 million netizens and 724 million mobile netizens as of 30 June 2017 (21). The report also claimed that people use the Internet for commerce transactions, finance, shopping, ordering meals, etc. Meanwhile, more and more people use the Internet to search for health-related information. In addition, the 2015 China Internet User Search Behavior Survey Report showed that $94.6 \%$ of the netizens used Baidu platform to search for information as of 31 December 2015. Baidu is the largest Chinese-language search engine and one of ten largest global websites. Baidu offers many services, including searching for websites, maps, videos, news, pictures, encyclopedia, multimedia files, translation, and other useful functions, as well as mobile service Baidu App (22).

Existing research has demonstrated that the availability of reliable health information for patients is of great importance; it can significantly increase self-efficacy, reduce anxiety, and enhance the self-care ability $(23,24)$. Notably, because of the low costs and rich resources, the Internet has become a major source for seeking health-related information, like providing options on how to access health services and professional advice $(25,26)$. Zhang et al. (27) find that $71.79 \%$ of Chinese adults have received health education on the Internet, and almost all (98.35\%) had searched online for health-related information. They further find that Baidu is one of the most popular tools for seeking healthrelated information in China. Moreover, Chen and Zhu (28) argue that the Internet is an alternative source of help in times of mental illness, especially for those with internalized stigma. As for the reasons for this phenomenon, a few studies suggested that online health-related information is especially suitable for internet users because of the low cost and rich resources $(29,30)$. Thus, when confronted with depression, compared with other available sources, the Internet may be a more proper source of information for people with internalized stigma and limited access to health care services (31). Besides, all Internet traces would be recorded on big data platforms, which provide the possibility of utilizing those online data to carry out research.

In recent years, the big data platform has been used in a variety of novel studies on public health. For example, it has been found that there is a significant correlation between the number of people searching for influenza-related topics in Google and epidemiologic surveillance data on influenza outbreaks from the Centers for Disease Control and Prevention (32). The Chinese big data platforms have also been used widely in public health for issues including disease development trends, predictions of epidemics, internet surveillance, and the assessment of the impact of an emerging infectious disease (33-36). The present study employs the big data platform to study the netizens' concern about depression. To be specific, the study aims to: 
(1) compare the depression-related netizens' concern before and after the suicide of Qiao; and (2) explore depression-related search characteristics on the Internet.

\section{MATERIALS AND METHODS Study Design}

According to the time of the Qiao's suicide, the study was divided into two periods (i.e., Period One from 1 September 2015 to 31 August 2016 and Period Two from 1 October 2016 to 30 September 2017). Each period contains 12 months. September 2016 was excluded from the study to avoid the impact of extreme data, since the suicide occurred in that month and definitely aroused significant attention in China within a short time.

\section{Data Collection}

The study used BDI (Baidu Index) to obtain information about age, gender, and geography. The age is divided into five groups (i.e., 10-19, 20-29, 30-39, 40-49, and above 50 years old). For the geographical features, this study selected the search volume T0P 10 cities (from 1 September 2015 to 30 September 2017). The study also used BDI to collect the Top 10 topics about depression from 1 September 2015 to 30 September 2017 on Baidu. Through these hot issues, we can learn what kind of information the netizens need.

To compare the netizens' concern about depression before and after the suicide of Qiao, this study collected the daily BDI for “抑郁症 depression” during two periods. The daily BDI for “自杀 suicide,” “精神分裂症 schizophrenia," “强 迫症 obsessive-compulsive disorder," “感冒 common cold," “胃癌 stomach cancer, and “肝癌 liver cancer," were also selected. For the parallel comparison, we count the daily SMI for “抑有症 depression.”

\section{Research Instrument}

Baidu Index is a systematic data-sharing platform based on Baidu search engine, which provides massive search behavior data (37). It provides its users with the search volume and trend for massive keywords and hot phrases, which can help to discover the changes of netizens' demands and monitor the trends of media netiznes' opinions. It calculates the "search volume index," which represents the number of searches for keywords or hot phrases on the Baidu search engine. The bigger the BDI means the bigger the search volume. In addition, BDI also provides basic geographic (city, provinces, and regions where search queries are originated) and demographic (age, group, and gender) characteristics of users who submitted search queries related to a given search keyword. As such, the daily BDI is a measurement of the relative attention on a topic at a specific time point.

The Sina Micro Index (SMI) is another Chinese data-sharing platform based on the Sina MicroBlog. As the most popular micro blog in China, the Sina MicroBlog had a large number of active users, $\sim 340$ million as of 31 March 2017 (38). This platform can serve as a keyword research tool; on the basis of mass user behavior data and blog data, it can reflect the trends of netizens' opinions and keywords with weights on different topics.
TABLE 1 | Baidu depression-related searchers-demographic and geographic.

1st period 2nd period 1 September 2015-

30 September 2017

\begin{tabular}{lccc}
\hline Age & & & \\
$10-19$ & $6 \%$ & $6 \%$ & $6 \%$ \\
$20-29$ & $24 \%$ & $20 \%$ & $20 \%$ \\
$30-39$ & $43 \%$ & $47 \%$ & $47 \%$ \\
$40-49$ & $25 \%$ & $26 \%$ & $25 \%$ \\
$\geq 50$ & $2 \%$ & $1 \%$ & $2 \%$ \\
Gender & & & \\
Male & $51 \%$ & $45 \%$ & $46 \%$ \\
Female & $49 \%$ & $55 \%$ & $54 \%$ \\
Rank of city & & & \\
1 & Beijing & Beijing & Beijing \\
2 & Shanghai & Shanghai & Shanghai \\
3 & Guangzhou & Guangzhou & Guangzhou \\
4 & Shenzhen & Shenzhen & Shenzhen \\
5 & Wuhan & Hangzhou & Hangzhou \\
6 & Tianjin & Chengdu & Chengdu \\
7 & Hangzhou & Wuhan & Wuhan \\
8 & Chengdu & Tianjin & Tianjin \\
9 & Nanjing & Chongaing & Nanjing \\
10 & Suzhou & Nanjing & Suzhou \\
\hline
\end{tabular}

\section{Statistical Analyses}

The study launched SPSS 19.0 to conduct statistical analysis. The paired $t$-test was used to compare the differences in search volumes between two periods. The Pearson correlation analysis was used to estimate correlations between the BDI and SMI for depression. A $p<0.05$ was considered statistically significant.

\section{RESULTS}

\section{Characteristics of Demographic and Geographic}

Table 1 summarized the brief demographic descriptions of those who performed depression-related search queries on Baidu. The characteristics of user profiles were analyzed over two periods. From 1 September 2015 to 30 September 2017, the depressionrelated search queries were largely performed by people aged 20-49 (92\%) and female (54\%). The depression-BDI top 10 cities were Beijing, Shanghai, Guangzhou, Shenzhen, Hangzhou, Wuhan, Chengdu, Suzhou, Tianjin, and Nanjing, almost all of which are the GDP top ten cities in China. Results also showed an increase in the female who concerned about depression in the second period.

\section{The Topics of Netizens Concern}

Table 2 presented the top 10 depression-related searched topics on Baidu. Three kinds of topics mostly being concerned were summed up; the first one was "common knowledge of depression," the second "treatment of depression," and the third "diagnosis of depression." It was also revealed that "common 
TABLE 2 | Top 10 depression-related topics on Baidu: 1 September 2015 to 30 September 2017

\begin{tabular}{ll}
\hline Rank & Depression-related topic \\
\hline 1 & What is depression? \\
2 & Is the depression-test accurate? \\
3 & How was Cui's depression cured? \\
4 & Treatment for depression \\
5 & How to treat depression? \\
6 & Can depression be cured? \\
7 & Self-treatment of depression \\
8 & What does depression look like? \\
9 & What are the symptoms of depression? \\
10 & What medicine does depression take?
\end{tabular}

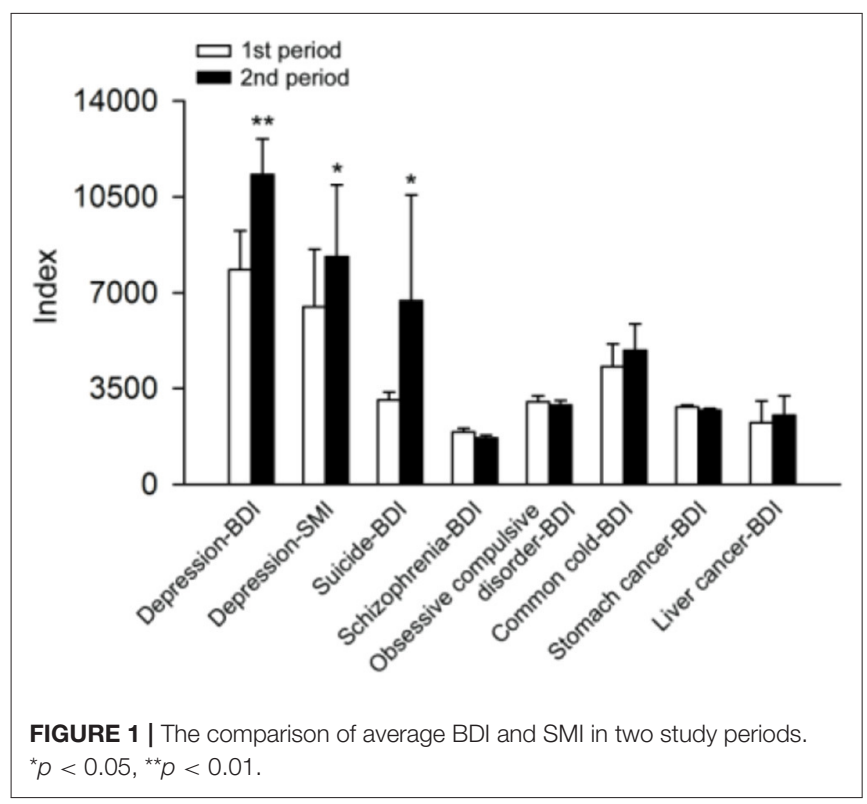

knowledge of depression" received the highest level of concern among the three topics.

\section{Comparisons of BDI and SMI in Two Study Periods}

Figure 1 showed that the average BDI for depression, suicideBDI and depression-SMI in Period Two were significantly higher than indexes in Period One $(P<0.05)$; the average BDI for schizophrenia in Period Two was significantly lower than the BDI in Period One $(P<0.05)$; additionally, there was no difference in Obsessive compulsive disorder-BDI, Common cold-BDI, Stomach cancer-BDI, and Liver cancer-BDI between two periods.

\section{The Trends of BDI and SMI}

The search interest for the Chinese term of “抑有症 depression” in BDI and SMI has increased steadily since 1 September 2015 and closely reflected the term “自杀 suicide" in BDI. The depression-BDI rapidly increased from 6,571 on 15 September
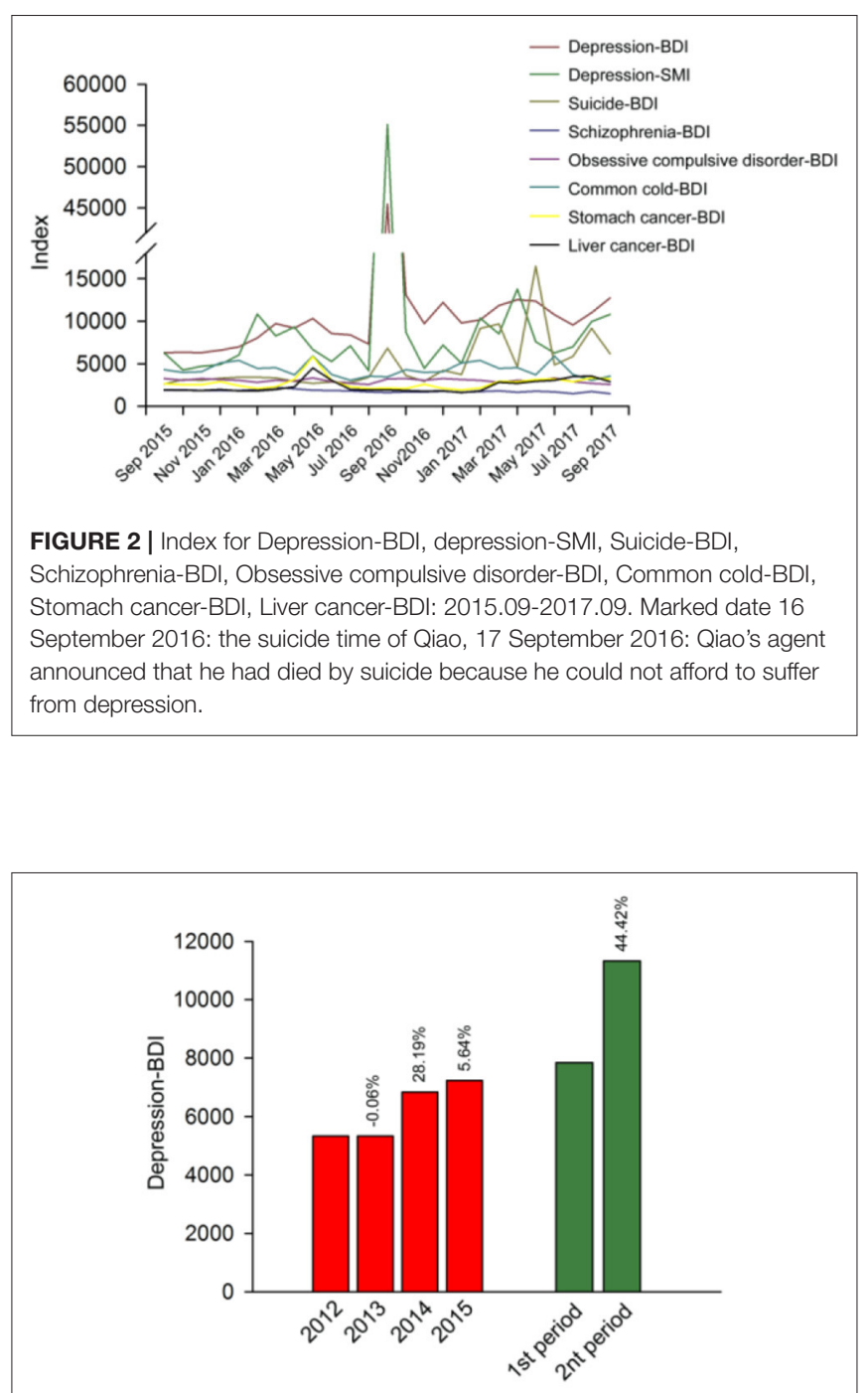

FIGURE 3 | The yearly average depression-BDI from 2012 to 2015 and average depression-BDI in two study periods. The percentage represents the growth rate relative to the previous year or period.

2016 to its peak at 472,797 on 17 September 2016, declined to 15,730 with fluctuations on 30 September, and stayed above the primary level before 16 September. Similarly, the depression SMI reached a peak of about 775,845 on 17 September, and gradually declined to 14,309 on 30 September. The average BDI for depression was significantly positively correlated with the average SMI for depression $(r=0.97, p<0.001)$. Furthermore, the BDI for schizophrenia, obsessive compulsive disorder, common cold, stomach cancer, and liver cancer in China were mapped in Figure 2, none of which show a positive trend. For the average BDI for depression, the annual rate of growth from 2012 to 2015 (11.26\%) was significantly lower than the increase $(44.42 \%)$ during the study time (see Figure 3). 


\section{DISCUSSION}

The present study examined whether the Chinese netizens pay more attention to depression after the Qiao's suicide. The results confirmed that view, and the paper also attempts to explore depression-related search characteristics on the Internet (This study investigated the differences in search-engine query patterns before and after the Qiao's suicide to monitor the changes of netizens' concern about depression).

We find that the number of people focusing on depression in China is increased year by year, especially in recent years. On the one hand, we need to acknowledge that the growing popularity of mobile networks has brought convenience to the general netizens in China, prompting more people to search for information on the Internet. According to Statistics Bulletin of China Communications Operation in 2016, China has 5,590,000 mobile phone base stations, of which 2,630,000 are 4G base stations, and 777 million $4 \mathrm{G}$ users (39). These big data illustrated the potential that people use the Internet to seek healthrelated information. People can easily get much health-related information on the Internet.

On the other hand, we have to recognize the netizens' inner demand for mental health. With the rapid economic development of China in the last two decades, the Chinese living standard has been greatly improved. Meanwhile, it also brought a hurried lifestyle and more stress to the Chinese people (40). Numerous studies have considered stress to be a potential environmental risk factor for many psychological and behavioral abnormalities, including depressive disorders (41-43). Similarly, there are some clues in this research. The depression-BDI top 10 cities in China were Beijing, Shanghai, Guangzhou, Shenzhen, Hangzhou, Wuhan, Chengdu, Suzhou, Tianjin, and Nanjing, which were almost in line with the Chinese government's announcement of the top 10 GDP cities in 2015 (44). The study also found that the vast majority of Baidu searches for "depression" came from users aged 20-49 (92\%). As known, people aged 20-49 are the main labor force in any country. This study thus offers some support for the relationship between stress and depression. Actually, previous studies had found that chronically persisting environmental and work-related stress could lead to depression $(45,46)$. However, some studies hold a different view that better quality of life promotes more netizens' awareness on mental health and more attention to depression (47-49). From the author's point of view, perhaps these two views are both at work.

In addition, the study showed that females were more concerned about depression than males. Although our results were unable to tell whether there were some important differences between males and females suffering depression, a few studies have reported that women were more likely to suffer from depression and exhibited more serious depressive symptoms than men $(50,51)$. A recent study reveals that women under high stress from both work and family are five times more likely to experience suicidal ideation (51). Nowadays, more Chinese women become irreplaceable in the occupational arena with a nearly $70 \%$ labor force participation rate (52). However, females are faced with higher work stress and conflict than males (53), they also had to bear the family stress and take traditional responsibilities such as household work and children's parenting (54). The family roles (daughter, wife, mother, sister, daughterin-law, etc.) and the social roles (colleague, leader, etc.) exist simultaneously, resulting in more conflict. Therefore, when it comes to female depression, it is essential to regard work and family stress as the combined exposure. Therefore, we suggest paying more attention to female depressive patients, especially those working females.

Suicide is the main cause of death among Chinese people aged 15-34 years, while in the global population aged 15-29 years, it is the second leading cause of death $(55,56)$. Apart from depression, there were a series of other risk factors for suicide including low levels of education, heavy work fatigue, low income, staying single, poor health condition, et cetera. A recent study revealed that people with high depression and high anxiety were 54.77 times more at risk for suicide, much higher than people with either high anxiety or high depression (56). Increasing work pressure of young Chinese adults might take responsibility for this phenomenon. The low socio-economic status caused by unemployment can be one of the risk factors for suicide, but the exposure to various stressful events of those employees cannot be ignored either (57). Working characteristics such as occupation types and periods have been proved to result in different levels of work stress $(58,59)$. If people have irregular working schedules such as rotating shift work and excessive working time, they will feel highly stressed and perform poorly in work, especially for medical staff and police officers (60). Besides, it is found that suicide ideation is common among employed populations (prevalence range: $3.1 \%$ to $27.5 \%$ ) and closely related to high work stress (61).

The increase in mobile phone users certainly can prompt more depression-related search volumes, but we should not ignore the major social events' impacts on the netizens' concern about depression. Table 2 involved Cui's topic, which has been discussed for more than a decade in China. Cui is a wellknown TV media personality and the story of his recovery from depression has brought hope and inspiration to many depressive patients and their families and friends. This demonstrates the positive guiding role of the media in public health.

Our study found that there were significant differences in the average BDI for depression, SMI for depression, and BDI for suicide between two periods, but other diseases did not show such difference. This is consistent with existing empirical evidence that depression is significantly related to suicide (62, 63). All these results suggest that the suicide of Qiao had actually caused more concern among netizens about depression. This was verified by the growth rates of BDI in Figure 3. These two depression-related events have caused great concern among netizens about depression, leading us to think seriously about the reasons behind it. Cui's event made more people realize that depression can be cured, but it is more important to make people aware that depression is a kind of disease like the common cold, but not a shameful thing. The suicide of Qiao revealed the concealment of depression. A person who looks sunny and works seriously may be a depressive patient. A few researchers have mentioned that more and more people 
are struggling with depression nowadays, but it was difficult to perceive (64-66).

The study acquired depression-related topics that people are concerned about as well. The topic "common knowledge of depression" received the highest level of concern. This topic contains "what is depression" and "what are depressive symptoms," meaning that many people lack common sense about depression in China. Previous studies have found that most people have low levels of mental health literacy in China, especially in remote rural areas $(67,68)$. In fact, this is a universal phenomenon in the developing world; Loh and Joshi (69) also claimed that Indians lack sufficient awareness of depression and are more likely to label their depressive symptoms as "tension" or "worry" (69). Limited mental health literacy often means poor treatment and lower recognition rates of mental illness, including depression (70, 71); in other words, better knowledge and more positive beliefs about depression are associated with positive response to treatment (72). Therefore, increasing people's awareness of depression should be given serious consideration, which can promote service utilization $(73,74)$.

In the past decade, psycho-education has been recognized as an effective way to provide information regarding psychological disorders and their treatments, encouraging patients and their families to actively cope with disorders, including depression $(75,76)$. The Chinese government and some health-related organizations have strengthened the education of common sense about depression in recent years. However, there is still much work that needs to be done, such as establishing professional organizations, training staff, improving education methods, and so on. The second topic people were concerned about was the treatment of depression, especially the therapeutic effects. A large number of people are not informed or are completely unaware of the therapeutic effects of depression. This may be because there are not enough resources to treat depression in China (77).

Actually, these problems not only exist in China, but also in other developing countries, even in the United States. A report conducted by Kataoka et al. (78) demonstrated that eighty percent of American youth cannot get access to mental health services. The third topic was the diagnosis of depression, especially the accuracy of the self-test scale. This means that a significant number of people want to measure or have measured whether they are depressive or not. From this, we infer that some people may prefer to self-test because of stigma. A previous report also shows a similar point of view that some Chinese depressive patients seek help from the Internet because of the stigma (79). This partly explains why there are so many depressive patients in China, and a lack of professional treatments.

Nowadays, more and more people search for information about depression on the Internet. This is a quite exciting phenomenon, which is of great help to the popularization of depression-related knowledge and the public improvement of national happiness. Intellectually, we need to recognize the fact that most people just know that they need to search for information about depression, but do not know how to identify what they really need and what is reliable. Not to mention those who are just attracted by advertising. Sadly, the Internet is riddled with unprofessional health-related information that misleads people to make wrong decisions and results in serious consequences eventually (80-82). A recent report by Zhang et al. (27) indicates that only fourteen percent of the Chinese believe that health-related information on the Internet is effective and professional. This situation presents us with a new challenge: How to convey professional health information to the netizens on the Internet or social media? It is a new problem that every country in the world needs to take into serious consideration. Our study provides a message about the role of celebrities in public health information transmission. Nevertheless, the publicity of celebrities committing suicide is a double-edged sword, which may be positive or negative. Consequently, we should report more positive aspects of depression-related reports to guide the netizens' understanding of depression.

Big data can give us clues that we have not been able to study before, but it still doesn't cover everything. During the study period, there were also news reports of government officials, university professors, college students, and others who died by suicide because of depression. While these events have led to netizens' increased awareness of depression, their impact on the study itself has been limited, as this paper focuses more on trend changes. Actually, besides some subject factors, there are possibly a series of objective factors such as seasons which also influence depression-related netizens' concern, which are quite complicated to study. Consequently, in order to concentrate more on our own theme, we only discuss the influence taken by social suicide incidents similar to Qiao's from the perspective of social psychology here, which we expect to provide reference to improve netizens' mental health.

While also considering the limitations of the study, we hope to be able to use more detailed data from the big data platform. This is beneficial to cross-sectional comparative studies and prospective studies. In the future, we also expect to use both online and offline resources to enrich our research.

\section{LIMITATIONS}

Several limitations exist with the use of BDI to examine the netizens' health concern. Firstly, BDI only captures data from Internet users. There are a large number of non-internet users in China, especially those in remote areas and who do not like surfing the Internet. Thus, we just considered our study objects as netizens instead of all of the population in China. Secondly, the study only used the Chinese term of “抑有症 depression" which might have limited access to data. Thirdly, although the study has described some basic information, there are still many discrepancies on search-engine query patterns for netizens with diverse sociodemographic backgrounds. For instance, the elderly populations are slower to adopt technology, including the internet. This factor cannot be ignored, since China is stepping into an aging society. Lastly, the search 
volume index was influenced by random factors, which is an unavoidable limitation.

\section{CONCLUSIONS}

The changes of search-engine query patterns indicated that the celebrity's suicide might be able to improve the netizens' concern about depression in China. The study suggests publishing more practical knowledge and advice on depression through the Internet and social media, to improve the netizens' mental health literacy and help people to cope with their depressive symptoms appropriately.

\section{DATA AVAILABILITY STATEMENT}

The original contributions presented in the study are included in the article/supplementary material, further inquiries can be directed to the corresponding author/s.

\section{REFERENCES}

1. Ent Sina. Qiao Renliang Company Statement: Reality is Cruel, All the Way Well. Available online at: http://ent.sina.com.cn/s/m/2016-09-17/docifxvyqvy6568978.shtml

2. World Health Organization. Depression and Other Common Mental Disorders Global Health Estimates. Available online at: http://www.who.int/mental_ health/management/depression/prevalence_global_health_estimates/en/

3. Krishnan V, Nestler EJ. The molecular neurobiology of depression. Nature. (2008) 455:894-902. doi: 10.1038/nature07455

4. Dubovsky SL, Ghosh BM, Serotte JC, Cranwell V. Psychotic depression: diagnosis, differential diagnosis, and treatment. Psychother Psychosom. (2020). doi: 10.1159/000511348. [Epub ahead of print].

5. Tye KM, Mirzabekov JJ, Warden MR, Ferenczi EA, Tsai HC, Finkelstein J, et al. Dopamine neurons modulate neural encoding and expression of depressionrelated behaviour. Nature. (2013) 493:537-41. doi: 10.1038/nature11740

6. Archer J, Bower P, Gilbody S, Lovell K, Richards D, Gask L, et al. Collaborative care for depression and anxiety problems. Cochrane Database Syst Rev. (2012) 10:CD006525. doi: 10.1002/14651858.CD006525.pub2

7. Gelenberg AJ. A review of the current guidelines for depression treatment. $J$ Clin Psychiatry. (2010) 71:e15. doi: 10.4088/JCP.9078tx1c

8. Adorjan K, Mulugeta S, Odenwald M, Ndetei DM, Osman AH, Hautzinger M, et al. [Psychiatric care of refugees in Africa and the middle east: challenges and solutions]. Nervenarzt. (2017) 88:974-82. doi: 10.1007/s00115-017-0365-4

9. Reuter K, Raugust S, Marschner N, Harter M. Differences in prevalence rates of psychological distress and mental disorders in inpatients and outpatients with breast and gynaecological cancer. Eur J Cancer Care (Engl). (2007) 16:222-230. doi: 10.1111/j.1365-2354.2006.00744.x

10. Yi S, Ngin C, Tuot S, Chhoun P, Fleming T, Brody C, et al. Utilization of traditional, complementary and alternative medicine and mental health among patients with chronic diseases in primary health care settings in Cambodia. Int J Ment Health Syst. (2017). 11:58. doi: 10.1186/s13033-017-0167-x

11. Wang J, Wu X, Lai W, Long E, Zhang X, Li W, et al. Prevalence of depression and depressive symptoms among outpatients: a systematic review and metaanalysis. BMJ Open. (2017) 7:e017173. doi: 10.1136/bmjopen-2017-017173

12. Guo J, Guan L, Fang L, Liu C, Fu M, He H, et al. Depression among chinese older adults: a perspective from hukou and health inequities. J Affect Disord. (2017) 223:115-120. doi: 10.1016/j.jad.2017.07.032

13. 21 Century Economic Network. The Survey of Depression (2017). Available online at: http://m.21jingji.com/article/20170331/herald/ 3125366e215208735e7fe14319564091.html (accessed November 1, 2016).

\section{AUTHOR CONTRIBUTIONS}

H-ZY designed the study, analyzed the data, data interpretation, drafted the manuscript, and revised new drafts based on input from co-authors. TF participated in data interpretation and drafted the manuscript. J-NZ and PK participated in the design of the study and the statistical analysis. Y-XW participated in the design of the study, collected data, and contributed to drafting the manuscript. All authors contributed to the article and approved the submitted version.

\section{ACKNOWLEDGMENTS}

This study was supported by the National Nature Science Foundation of China (grant numbers 81372122 and 81771301), and the National Chronic Diseases Research Plan of China (grant number 2016YFC1307105).

14. Zhong BL, Chen HH, Zhang JF, Xu HM, Zhou C, Yang F, et al. Prevalence, correlates and recognition of depression among inpatients of general hospitals in Wuhan, China. Gen Hosp Psychiatry. (2010) 32:268-75. doi: 10.1016/j.genhosppsych.2010.01.016

15. Han YC, Zong YH, Zhang YH, Wang WH, Hui XQ, Wu X. Clinical analysis of somatic symptoms in 117 cases with major depression. Chin Ment Health J. (2008) 22:874-7. doi: 10.1016/S1872-2075(08)60026-6

16. Shi S, Lu Z, Zhu S. [Seeking behavior of patients with mental disorders and interfering factors]. Zhonghua Yi Xue Za Zhi. (2000) 80:75-8.

17. Lee S, Tsang A, Kwok K. Twelve-month prevalence, correlates, and treatment preference of adults with DSM-IV major depressive episode in Hong Kong. J Affect Disord. (2007) 98:129-36. doi: 10.1016/j.jad.2006.07.009

18. Kleinman A. Culture and depression. N Engl J Med. (2004) 351:951-3. doi: 10.1056/NEJMp048078

19. Lee S, Chiu MY, Tsang A, Chui H, Kleinman A. Stigmatizing experience and structural discrimination associated with the treatment of schizophrenia in Hong Kong. Soc Sci Med. (2006) 62:1685-96. doi: 10.1016/j.socscimed.2005.08.016

20. Fung KM, Tsang HW, Corrigan PW, Lam CS, Cheung WM. Measuring selfstigma of mental illness in China and its implications for recovery. Int J Soc Psychiatry. (2007) 53:408-18. doi: 10.1177/0020764007078342

21. China Internet Network Information Center. The 40th China Statistical Report on Internet Development. Available online at: http://www.cnnic.net.cn/ hlwfzyj/hlwxzbg/hlwtjbg/ (accessed November 7, 2017).

22. Wikipedia. Baidu. (2017). Available online at: https://en.wikipedia.org/wiki/ Baidu (accessed November 1, 2017).

23. Haymes AT. The quality of rhinoplasty health information on the internet. Ann Plast Surg. (2016) 76:143-9. doi: 10.1097/SAP.0000000000000660

24. Hart M, Stetten N, Islam S, Pizarro K. Twitter and public health (part 2): qualitative analysis of how individual health professionals outside organizations use microblogging to promote and disseminate health-related information. JMIR Public Health Surveill. (2017) 3:e54. doi: 10.2196/publichealth.6796

25. Zhao Y, Zhang J. Consumer health information seeking in social media: a literature review. Health Info Libr J. (2017) 34:268-83. doi: 10.1111/hir. 12192

26. Moreland J, French TL, Cumming GP. The prevalence of online health information seeking among patients in scotland: a cross-sectional exploratory study. JMIR Res Protoc. (2015) 4:e85. doi: 10.2196/resprot.4010

27. Zhang X, Wen D, Liang J, Lei J. How the public uses social media wechat to obtain health information in china: a survey study. BMC Med Inform Decis Mak. (2017) 17:66. doi: 10.1186/s12911-017-0470-0 
28. Chen J, Zhu S. Online information searches and help seeking for mental health problems in urban China. Adm Policy Ment Health. (2016) 43:535-5. doi: 10.1007/s10488-015-0657-6

29. Bao H, Zhu F, Wang F, Liu Z, Bao MH, He S, et al. Scoliosis related information on the internet in china: can patients benefit from this information? PLoS One. (2015) 10:e0118289. doi: 10.1371/journal.pone.0118289

30. Lou $\mathrm{CH}$, Zhao Q, Gao ES, Shah IH. Can the internet be used effectively to provide sex education to young people in China? J Adolesc Health. (2006) 39:720-8. doi: 10.1016/j.jadohealth.2006.04.003

31. Phillips MR, Pearson V, Li F, Xu M, Yang L. Stigma and expressed emotion: a study of people with schizophrenia and their family members in china. $\mathrm{Br} J$ Psychiatry. (2002) 181:488-93. doi: 10.1192/bjp.181.6.488

32. Ginsberg J, Mohebbi MH, Patel RS, Brammer L, Smolinski MS, Brilliant, et al. Detecting influenza epidemics using search engine query data. Nature. (2009) 457:1012-4. doi: 10.1038/nature07634

33. Yang H, Li S, Sun L, Zhang X, Hou J, Wang, et al. Effects of the ambient fine particulate matter on public awareness of lung cancer risk in China: evidence from the internet-based big data platform. JMIR Public Health Surveill. (2017) 3:e64. doi: 10.2196/publichealth.8078

34. Fung IC, Fu KW, Ying Y, Schaible B, Hao Y, Chan $\mathrm{CH}$, et al. Chinese social media reaction to the mers-cov and avian influenza a(h7n9) outbreaks. Infect Dis Poverty. (2013) 2:31. doi: 10.1186/2049-9957-2-31

35. Gu Y, Chen F, Liu T, Lv X, Shao Z, Lin H, et al. Early detection of an epidemic erythromelalgia outbreak using baidu search data. Sci Rep. (2015) 5:12649. doi: 10.1038/srep12649

36. Yuan Q, Nsoesie EO, Lv B, Peng G, Chunara R, Brownstein JS, et al. Monitoring influenza epidemics in china with search query from baidu. PLoS One. (2013) 8:e64323. doi: 10.1371/journal.pone.0064323

37. Baidu Index. Product Introduction. Available online at: http://index.baidu. com/Helper (accessed November 1, 2017).

38. Sina Technology. The Sina MicroBlog released the first quarter financial report in 2017. Available online at: http://tech.sina.com.cn/i/2017-05-16/docifyfeius8004650.shtml (accessed November 1, 2017).

39. Ministry of Industry and Information Technology of the People's Republic of China. Statistics Bulletin of China Communications Operation in 2016. Available online at: http://www.miit.gov.cn/n1146312/n1146904/n1648372/ c5498087/content.html (accessed November 1, 2017).

40. Zhang QL, Zhao LG, Zhang W, Li HL, Gao J, Han LH, et al. Combined impact of known lifestyle factors on total and cause-specific mortality among chinese men: a prospective cohort study. Sci Rep. (2017) 7:5293. doi: 10.1038/s41598-017-05079-5

41. Chaudhury D, Walsh JJ, Friedman AK, Juarez B, Ku SM, Koo JW, et al. Rapid regulation of depression-related behaviours by control of midbrain dopamine neurons. Nature. (2013) 493:532-6. doi: 10.1038/nature11713

42. Caspi A, Sugden K, Moffitt TE, Taylor A, Craig IW, Harrington H, et al. Influence of life stress on depression: moderation by a polymorphism in the 5-htt gene. Science. (2003) 301:386-9. doi: 10.1126/science.1083968

43. Pittenger C, Duman RS. Stress, depression, and neuroplasticity: a convergence of mechanisms. Neuropsychopharmacology. (2008) 33:88-109. doi: 10.1038/sj.npp.1301574

44. China GDP Database. National Bureau of Statistics of China. Available online at: http://data.stats.gov.cn/easyquery.htm?cn=E0105 (accessed November 1, 2017).

45. Bakusic J, Schaufeli W, Claes S, Godderis L. Stress, burnout and depression: a systematic review on DNA methylation mechanisms. J Psychosom Res. (2017) 92:34-44. doi: 10.1016/j.jpsychores.2016.11.005

46. Uchida S, Hara K, Kobayashi A, Otsuki K, Yamagata H, Hobara T, et al. Epigenetic status of gdnf in the ventral striatum determines susceptibility and adaptation to daily stressful events. Neuron. (2011) 69:359-72. doi: 10.1016/j.neuron.2010.12.023

47. Behzadifar M, Abdi S, Arabsalmani M, Saroukhani M, Sayehmiri K. The role of socioeconomic status on health-related quality of life in the west of iran. $J$ Clin Diagn Res. (2016) 10, LC10-13. doi: 10.7860/JCDR/2016/18349.8189

48. Strine TW, Kroenke K, Dhingra S, Balluz LS, Gonzalez O, Berry JT, et al. The associations between depression, health-related quality of life, social support, life satisfaction, and disability in community-dwelling US adults. J Nerv Ment Dis. (2009) 197:61-4. doi: 10.1097/NMD.0b013e3181924ad8
49. Kim YC, Park CI, Kim DY, Kim TS, Shin JC. Statistical analysis of amputations and trends in Korea. Prosthet Orthot Int. (1996) 20:88-95. doi: 10.3109/03093649609164424

50. Yusuf L. Depression, anxiety and stress among female patients of infertility; a case control study. Pak J Med Sci. (2016) 32:1340-3. doi: 10.12669 /pjms.326.10828

51. Fodor A, Kovacs KB, Balazsfi D, Klausz B, Pinter O, Demeter K, et al Depressive- and anxiety-like behaviors and stress-related neuronal activation in vasopressin-deficient female brattleboro rats. Physiol Behav. (2016) 158:100-11. doi: 10.1016/j.physbeh.2016.02.041

52. Lin $\mathrm{W}$, Wang $\mathrm{H}$, Gong $\mathrm{L}$, Lai $\mathrm{G}$, Zhao $\mathrm{X}$, Ding $\mathrm{H}$, et al. Work stress, family stress, and suicide ideation: a cross-sectional survey among working women in Shenzhen, China. J Affect Disord. (2020) 277:747-54. doi: 10.1016/j.jad.2020.08.081

53. Zhuo LB, Yao W, Yan Z, Giron MST, Pei JJ, Wang HX. Impact of effort reward imbalance at work on suicidal ideation in ten European countries: the role of depressive symptoms. J Affect Disord. (2020) 260:214-21. doi: 10.1016/j.jad.2019.09.007

54. Lundberg U. Influence of paid and unpaid work on psychophysiological stress responses of men and women. J Occup Health Psychol. (1996) 1:117-30. doi: 10.1037/1076-8998.1.2.117

55. Gjerdingen D, McGovern P, Bekker M, Lundberg U, Willemsen T. Women's work roles and their impact on health, well-being, and career: comparisons between the United States, Sweden, and The Netherlands. Women Health. (2000) 31:1-20. doi: 10.1300/J013v31n04_01

56. Zhang J, Conwell Y, Zhou L, Jiang C. Culture, risk factors and suicide in rural China: a psychological autopsy case control study. Acta Psychiatr Scand. (2004). 110:430-7. doi: 10.1111/j.1600-0447.2004.00388.x

57. Zhang J, Liu X, Fang L. Combined effects of depression and anxiety on suicide: a case-control psychological autopsy study in rural China. Psychiatry Res. (2019) 271: p. 370-373. doi: 10.1016/j.psychres.2018.11.010

58. Dalglish SL, Melchior M, Younes N, Surkan PJ. Work characteristics and suicidal ideation in young adults in France. Soc Psychiatry Psychiatr Epidemiol. (2015) 50:613-20. doi: 10.1007/s00127-014-0969-y

59. Muschalla B, Linden M. Different workplace-related strains and different workplace-related anxieties in different professions. J Occup Environ Med. (2013) 55:978-82. doi: 10.1097/JOM.0b013e3182972f04

60. Loerbroks A, Cho SI, Dollard MF, Zou J, Fischer JE, Jiang Y, et al. Associations between work stress and suicidal ideation: Individual-participant data from six cross-sectional studies. J Psychosomat Res. (2016) 90:62-9. doi: 10.1016/j.jpsychores.2016.09.008

61. Lin PC, Chen CH, Pan SM, Chen YM, Pan CH, Hung HC, et al. The association between rotating shift work and increased occupational stress in nurses. J Occup Health. (2015) 57:307-15. doi: 10.1539/joh.13-0284-OA

62. Adan A, Marquez-Arrico JE, Gilchrist G. Comparison of health-related quality of life among men with different co-existing severe mental disorders in treatment for substance use. Health Qual Life Outcomes. (2017) 15:209. doi: 10.1186/s12955-017-0781-y

63. Szerman N, Lopez-Castroman J, Arias F, Morant C, Babin F, Mesias B, et al Dual diagnosis and suicide risk in a spanish outpatient sample. Subst Use Misuse. (2012) 47:383-9. doi: 10.3109/10826084.2011.636135

64. Tsutsumi A, Kawakami N. A review of empirical studies on the model of effort-reward imbalance at work: reducing occupational stress by implementing a new theory. Soc Sci Med. (2004) 59:2335-59. doi: 10.1016/j.socscimed.2004.03.030

65. Yusoff MS, Abdul Rahim AF, Baba AA, Ismail SB, Mat Pa MN, Esa AR, et al. Prevalence and associated factors of stress, anxiety and depression among prospective medical students. Asian J Psychiatr. (2013) 6:128-33. doi: 10.1016/j.ajp.2012.09.012

66. Wiegner L, Hange D, Bjorkelund C, Ahlborg G Jr. Prevalence of perceived stress and associations to symptoms of exhaustion, depression and anxiety in a working age population seeking primary care-an observational study. BMC Fam Pract. (2015) 16:38. doi: 10.1186/s12875-015-0252-7

67. Yu Y, Hu M, Liu ZW, Liu HM, Yang JP, Zhou L, et al. Recognition of depression, anxiety, and alcohol abuse in a chinese rural sample: a cross-sectional study. BMC Psychiatry. (2016) 16:93. doi: 10.1186/s12888-016-0802-0 
68. Wong DF, Xuesong H, Poon A, Lam AY. Depression literacy among chinese in Shanghai, China: a comparison with chinese-speaking australians in Melbourne and Chinese in Hong Kong. Soc Psychiatry Psychiatr Epidemiol. (2012) 47:1235-42. doi: 10.1007/s00127-011-0430-4

69. Loh DA, Joshi A, Taku K, Mendelsohn N, Katz CL. Knowledge and attitudes towards clinical depression among community medical providers in Gujarat, India. Psychiatr Q. (2017) 89:249-59. doi: 10.1007/s11126-017-9530-y

70. Meadows G, Burgess P, Bobevski I, Fossey E, Harvey C, Liaw ST, et al. Perceived need for mental health care: influences of diagnosis, demography and disability. Psychol Med. (2002) 32:299-309. doi: $10.1017 /$ S0033291701004913

71. Mojtabai R, Olfson M, Mechanic D. Perceived need and help-seeking in adults with mood, anxiety, or substance use disorders. Arch Gen Psychiatry. (2002) 59:77-84. doi: 10.1001/archpsyc.59.1.77

72. Jorm AF. Mental health literacy: empowering the community to take action for better mental health. Am Psychol. (2012) 67:231-43. doi: 10.1037/a0025957

73. Wright A, Jorm AF, Harris MG, McGorry PD. What's in a name? Is accurate recognition and labelling of mental disorders by young people associated with better help-seeking and treatment preferences? Soc Psychiatry Psychiatr Epidemiol. (2007) 42:244-50. doi: 10.1007/s00127-006-0156-x

74. Jorm AF, Nakane Y, Christensen H, Yoshioka K, Griffiths KM, Wata $\mathrm{Y}$, et al. Public beliefs about treatment and outcome of mental disorders: A comparison of Australia and Japan. BMC Med. (2005) 3:12. doi: 10.1186/1741-7015-3-12

75. Altweck L, Marshall TC, Ferenczi N, Lefringhausen K. Mental health literacy: a cross-cultural approach to knowledge and beliefs about depression, schizophrenia and generalized anxiety disorder. Front Psychol. (2015) 6:1272. doi: 10.3389/fpsyg.2015.01272

76. Chou $\mathrm{MH}$, Lin MF, Hsu MC, Wang $\mathrm{YH}$, Hu HF. Exploring the self-learning experiences of patients with depression participating in a multimedia education program. J Nurs Res. (2004) 12:297-306. doi: 10.1097/01.JNR.0000387514.75114.75
77. Hu TW, He Y, Zhang M, Chen N. Economic costs of depression in China. Soc Psychiatry Psychiatr Epidemiol. (2007) 42:110-6. doi: 10.1007/s00127-006-0151-2

78. Kataoka SH, Zhang L, Wells KB. Unmet need for mental health care among US children: variation by ethnicity and insurance status. Am J Psychiatry. (2002) 159:1548-55. doi: 10.1176/appi.ajp.159.9.1548

79. Chen J. Seeking help for psychological distress in urban China. J Commun Psychol. (2012) 40:319-41. doi: 10.1002/jcop.20513

80. Griffiths KM, Christensen H. Review of randomised controlled trials of internet interventions for mental disorders and related conditions. Clin Psychol. (2006) 10:16-29. doi: 10.1080/132842005003 78696

81. Barak A, Hen L, Boniel-Nissim M, Shapira NA. A comprehensive review and a meta-analysis of the effectiveness of internet-based psychotherapeutic interventions. J Technol Hum Serv. (2008) 26:109-60. doi: 10.1080/15228830802094429

82. Arnberg FK, Linton SJ, Hultcrantz M, Heintz E, Jonsson U. Internet-delivered psychological treatments for mood and anxiety disorders: a systematic review of their efficacy, safety, and cost-effectiveness. PLoS One. (2014) 9:e98118. doi: 10.1371/journal.pone.0098118

Conflict of Interest: The authors declare that the research was conducted in the absence of any commercial or financial relationships that could be construed as a potential conflict of interest.

Copyright (c) $2021 \mathrm{Yu}, \mathrm{Fu}, \mathrm{Zhou}, \mathrm{Ke}$ and Wang. This is an open-access article distributed under the terms of the Creative Commons Attribution License (CC BY). The use, distribution or reproduction in other forums is permitted, provided the original author(s) and the copyright owner(s) are credited and that the original publication in this journal is cited, in accordance with accepted academic practice. No use, distribution or reproduction is permitted which does not comply with these terms. 